\title{
GENDER DIFFERENCES IN PTSD: AN EXPLORATION OF PERITRAUMATIC FACTORS
}

\author{
A thesis submitted \\ to Kent State University in partial \\ fulfillment of the requirements for the \\ degree of Master of Arts
}

by

Leah Irish

December, 2007 
Thesis written by Leah Irish

B.S. University of Wisconsin-Whitewater, 2003

M.A., Kent State University, 2007

Approved by

Douglas L. Delahanty

Mary Ann Stephens

Jerry Feezel , Advisor , Chair, Department of Psychology , Dean, College of Arts and Sciences 
TABLE OF CONTENTS

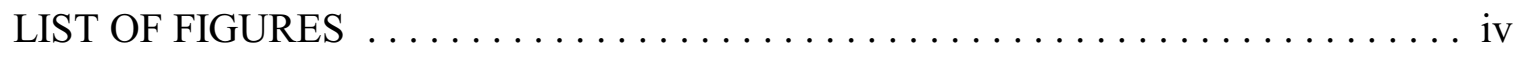

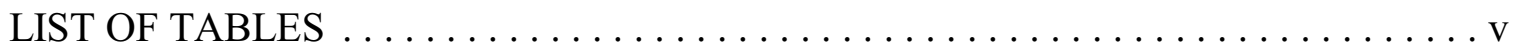

CHAPTER $\quad$ Page

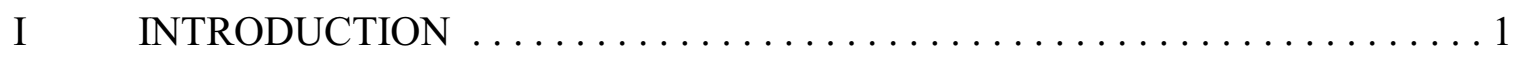

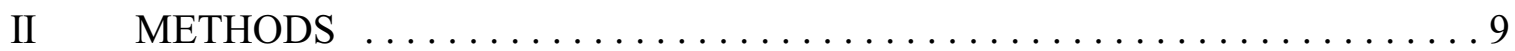

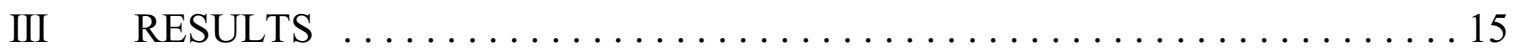

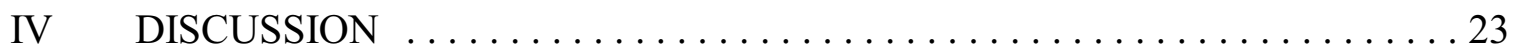

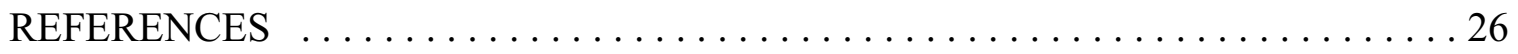

APPENDIX

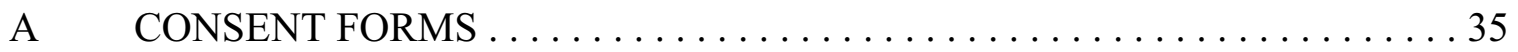

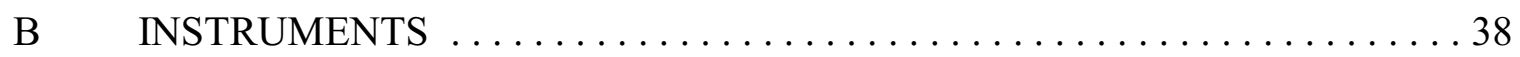




\section{LIST OF FIGURES}

Figure

Page

1 Results of mediation models examining gender, initial symptoms and development of PTSD symptoms six weeks and six months post-MVA . . . . 20

2 Results of mediation models examining gender, mastery and development of PTSD symptoms six weeks and six months post-MVA. . . . . . . . . 22 


\section{LIST OF TABLES}

Table

Page

1 Means, Standard Deviations and Results of One Way ANOVAs examining gender differences in peritraumatic responses, demographic

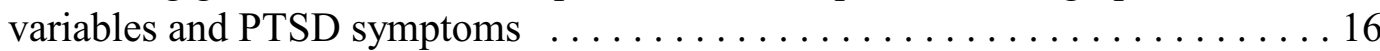

2 Bivariate Correlations among peritraumatic responses, demographic

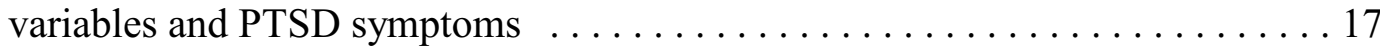




\section{CHAPTER 1}

\section{INTRODUCTION}

According to the Diagnostic and Statistical Manual of Mental Disorders- Fourth Edition, events may be considered traumatic only if they involve actual or threatened harm that is accompanied by feelings of intense fear, horror or helplessness (American Psychiatric Association, 1994). Such events are quite common in the United States, with approximately two-thirds of Americans reporting exposure to at least one traumatic event during their lifetime and many reporting repeated trauma exposure (Breslau et al., 1998; Kessler, Sonnega, Bromet, Hughes \& Nelson, 1995; Norris, 1992). In the aftermath of a trauma, victims commonly report experiencing posttraumatic stress disorder (PTSD) symptoms. There are three symptom clusters associated with PTSD - re-experiencing, avoidance and hyperarousal. Re-experiencing refers to unwanted and intrusive recollections of the trauma, such as flashbacks or vivid nightmares. Avoidant thoughts and behaviors may include reluctance to talk about the event or attempts to avoid reminders of the trauma as well as symptoms of emotional numbing. Hyperarousal may be experienced in many ways including hypervigilance, trouble falling and staying asleep or exaggerated startle response. If symptoms persist for more than one month, individuals can be diagnosed with PTSD (American Psychiatric Association, 1994). 
Although most trauma victims experience PTSD symptoms soon after a trauma, only a small but significant minority go on to develop PTSD. For example, Riggs and colleagues (1995) found that in the days after an assault, 50\% of men and 70\% of women suffered from moderate to severe PTSD symptoms, but four months later these symptoms affected only $21 \%$ of women and none of the men.

Although rates of exposure to traumatic events are generally lower for females than males, epidemiological studies have consistently found that females are approximately twice as likely as males to develop PTSD (Breslau et al., 1998; Kessler et al., 1995). A recent meta-analysis by Tolin and Foa (2006) addressed gender differences in PTSD and trauma exposure and confirmed that females are at greater risk for developing PTSD even though they are less likely to be exposed to traumatic events. Further, results revealed that differential exposure to specific types of trauma (i.e. sexual assault) couldn’t fully account for these differences. A number of individual and traumarelated characteristics have been hypothesized to contribute to this sex-specific risk including differences in exposure to sexual assault, differences in psychophysiology, and differences in appraisal of threat and control, dissociation, coping style and social support (see review by Olff, Langeland, Draijer \&Gersons, 2007). A recent meta-analysis of PTSD risk factors has suggested that peritraumatic responses to trauma may be stronger predictors of PTSD development than pre-trauma variables (i.e. trauma history) or posttrauma variables (i.e. social support; Ozer, Best, Lipsey \& Weiss, 2003). Thus, the current investigation examined the extent to which initial traumatic reactions contribute to gender differences in PTSD symptom development. 
Early identification of individuals at high risk for PTSD has become a major goal of trauma research. Generally, trauma victims have the most contact with service professionals (e.g. doctors, counselors) in the days following the trauma, providing the most opportunity for intervention. Thus, a number of factors (e.g., appraisals, emotional responses) present in the acute aftermath of trauma have been identified as predictors of subsequent symptom development.

Theoretical and empirical studies have suggested that an individual's perceptions and emotional responses during a trauma may be related to posttraumatic distress. Trauma-related characteristics, such as perceived life threat and injury severity have been examined as predictors of PTSD risk, and may help account for gender differences. Objective observations of injury severity by medical personnel have typically failed to predict development of PTSD symptoms (Bryant \& Harvey, 1995; Curran et al., 1990; Ehlers, Mayou \& Bryant, 1998; Perry, Difede, Musngi, Frances \& Jacobsberg, 1992) with a few exceptions (Blanchard et al., 1995; Delahanty, Raimonde, Spoonster \& Cullado, 2003). However, trauma victims’ subjective perceptions of life threat have consistently been related to PTSD symptom development, such that greater perceived threat predicts greater PTSD risk (Bernat, Ronfeldt, Calhoun \& Arias, 1998; Blanchard et al., 1995; Dunmore, Clark \& Ehlers, 1999; Ehlers et al., 1998; Kilpatrick et al., 1989). Across studies, effect sizes range from small to medium (Ozer et al., 2003). Overall, empirical findings suggest greater predictive power of perceived threat and injury over actual injury, which suggests that PTSD vulnerability is affected more by cognitive appraisal than actual physical injury. 
Cognitive models of trauma response focus on the role of appraisal in evaluating the threat of a traumatic event and the ability to cope with that threat. It is hypothesized that when a trauma victim appraises the event as catastrophic, they continue to feel threatened, even after the event has passed. This constant feeling of danger likely worsens symptoms of posttraumatic stress because the victim is unable to return to an adaptive stress response (Ehlers \& Clark, 2000). Two victims may suffer very similar events and injuries, but individual appraisals of threat, emotional distress and resource strain can lead to completely different outcomes. Clearly, a catastrophic appraisal of the event is more likely to lead to psychopathology. In general, negative cognitive appraisals of a traumatic event are associated with increased risk for posttraumatic disorders (Dunmore et al., 1999; Ehlers et al., 1998; Nixon \& Bryant, 2005).

In a study of earthquake survivors, Karanci and colleagues (1999) found that women reported a greater sense of threat from the earthquake than men, and that perceived threat predicted psychological distress in women, but not in men. Solomon and colleagues (2005) reported similar findings following terrorist attacks. Additional research has examined trauma victims’ feelings of intense fear, helplessness and horror, and demonstrated a positive association between these emotional responses immediately following a trauma and development of PTSD symptoms (Ozer et al., 2003). Studies specifically comparing gender differences in perceptions of fear, horror and helplessness revealed that women are more likely than men to view comparable events as threatening (see Norris, Foster \& Weisshaar, 2002). Although few studies to date have examined perceived life threat of a trauma as an explanation for female vulnerability in PTSD 
development, the existing evidence appears promising. The theoretical constructs of cognitive trauma models provide a reasonable framework for examining these associations.

In addition to perceived threat, peritraumatic dissociation may also have longterm effects on symptom development. Peritraumatic dissociation is an altered sense of reality experienced during the trauma. Victims may experience unrealistic perceptions of time, person and place, which may include disbelief that the event is really happening to them, feeling disconnected from one's own body, or feeling that time has slowed down or accelerated (Marmar, Weiss \& Metzler, 1997). The association between peritraumatic dissociation and PTSD is well documented, suggesting that trauma victims who report more dissociation are at greater risk for developing PTSD (Ehlers et al., 1998; Koopman, Classen \& Speigel, 1994; Shalev et al., 1998; Ursano et al., 1999; see meta-analysis by Ozer et al., 2003). Peritraumatic dissociation is posited to be harmful to trauma victims because it may lead to inadequate consolidation of the traumatic memory. As a result, the victim may be unable to adequately process trauma-related cognitions and emotions, and therefore fail to engage in an adaptive stress response (Koopman et al., 1994).

While PTSD cannot be officially diagnosed until one month after the trauma, posttraumatic stress symptoms are often observed soon after the traumatic event. A combination of acute intrusive, avoidant and hyperarousal symptoms have been reported in the days and weeks following a traumatic event, and shown to predict development of later PTSD symptoms in a variety of trauma populations (Bryant \& Harvey, 1996; Cardeña \& Spiegel, 1993; Feinstein \& Dolan, 1991; North, Smith \& Spitznagel, 1994; 
Richmond \& Kauder, 2000; Rothbaum, Foa, Riggs, Murdock \& Walsh, 1992). The diagnosis of acute stress disorder (ASD) was established as an acute marker for individuals at high risk for PTSD. Diagnosis of ASD is based on re-experiencing, avoidance, hyperarousal and dissociative symptoms that appear between two days and four weeks post-trauma (American Psychiatric Association, 1994). ASD diagnosis has been shown to significantly predict development of PTSD symptoms 3-24 months after the trauma (Birmes et al., 2005; Brewin, Andrews, Rose \& Kirk, 1999; Classen, Koopman, Hales \& Spiegel, 1998; Harvey \& Bryant, 1998; Harvey \& Bryant, 1999). Despite these results, some have argued that ASD diagnosis is not a reliable predictor of PTSD development because it requires the presence of dissociative symptoms which may only appear in a subset of trauma victims (see Bryant, 2007). Richmond and Kauder (2000) examined a sample of motor vehicle accident (MVA) victims and found that inhospital intrusive and avoidance symptoms significantly predicted development of PTSD symptoms three months later. Birmes and colleagues (2005) tested a model including both peritraumatic dissociation and acute symptoms as predictors of PTSD development. Results revealed that both accounted for significant and unique variance in PTSD. Clearly, further investigation of both peritraumatic dissociation and initial symptoms will improve our understanding of PTSD risk.

In general, studies of acute stress symptoms typically do not focus on gender differences. However, when gender effects are reported, women consistently report more acute stress symptoms than men (Bryant \& Harvey, 2003; Elkilt, 2002; Fullerton et al., 2001). Females also appear to engage in more peritraumatic dissociation than males 
(Bryant \& Harvey, 2003; Ehlers et al., 1998; Grieger, Fullerton \& Ursano, 2003; Lawyer et al., 2006) although not all studies report this effect (Punamaki, Komproe, Qouta, Elmasri \& de Iong, 2005). Overall, these findings encourage consideration of acute symptoms and peritraumatic dissociation as explanations for sex specific risk for PTSD.

A final variable to consider in the examination of gender differences is the extent to which men and women feel they have a sense of mastery, or control over events that occur in their lives. When trauma victims believe they have the ability to alter their life circumstances, they are less likely to exaggerate the severity of potential danger or ruminate on what has happened to them. In addition, they are more likely to engage in effective coping strategies and more motivated to remove themselves from potentially harmful environments (Benight \& Bandura 2004). Studies have found that individuals who report low mastery/self-efficacy suffer more posttraumatic distress than those who report high mastery/self-efficacy (Benight et al., 2000; Benight, Ironson \& Durham, 1999; Murphy, 1987), and interventions focused on improving coping self-efficacy have been successful at reducing PTSD symptoms (Freuh, Turner, Beidel, Mirabella \& Jones, 1996; Ozer and Bandura, 1990). On the other hand, individuals who believe they have control over their current response to the trauma and over the chance of the trauma happening again appear to be more resilient to developing PTSD (see review by Frazier, Berman \& Steward, 2002). Women tend to report a lower sense of control than men (Karanci et al., 1999; Rubinstein, 2004; Solomon, Gelkopf \& Bleich, 2005). This may be at least partially explained by the tendency for women to experience greater work load and role strain than men, and by women's lower socioeconomic status (Cassidy \& 
Davies, 2003; Nolen-Hoeksema, Larson \& Grayson, 1999). Overall, research has demonstrated gender differences in mastery, perceived life threat, peritraumatic dissociation and initial PTSD symptoms, and shown that these factors are all consistent predictors of posttraumatic distress. However, it remains to be seen whether peritraumatic factors can explain gender differences.

The purpose of the present study was to examine gender differences in initial symptoms, peritraumatic dissociation, mastery and perceived life threat. These peritraumatic factors were tested as mechanisms through which gender may contribute to differences in the development of PTSD symptoms following a MVA. We hypothesized that gender differences would exist in initial symptoms, peritraumatic dissociation, perceived mastery and perceived life threat, and that these factors would at least partially explain increased PTSD risk in females. Specifically, it was predicted that female gender would be associated with more severe PTSD symptoms both six weeks and six months post MVA and that this would be at least partially accounted for by higher initial symptoms in hospital, more peritraumatic dissociation, greater perception of life threat as a result of their accident and less perceived mastery. In order to distinguish actual life threat from perceived life threat, objective injury severity was examined as a control variable in the life threat model. In addition, while mastery is a general concept and does not refer specifically to control over the accident, we expected that passenger vs. driver status would affect victims' feelings of control, and therefore it was considered as a control variable in the mastery model. 


\section{CHAPTER 2}

\section{METHODS}

\section{Participants}

Three hundred fifty-seven non-amnestic MVA victims (210 men and 147 women) were recruited following admission to a hospital trauma unit. The age of participants ranged from 18-87 (mean=38.60) and average household income was $\$ 20,000-30,000$ per year. The sample was primarily Caucasian (88.0\%) with 10.2\% African American and $1.8 \%$ other ethnicities. This racial distribution is consistent with the demographics of the Northeast Ohio area. At the six-week follow up, 16 participants (3 males and 13 females) met diagnostic criteria for PTSD and 33 participants (8 males and 25 females) met diagnostic criteria for major depression. At six months, 15 (2 males and 13 females) met criteria for PTSD and 26 (9 males and 17 females) were clinically depressed.

For the six-week follow-up, 249 participants (139 males and 110 females) were retained, and 194 (101 males and 93 females) were retained for the six-month follow-up. Comparison of those who remained in the study and those who did not revealed that males were more likely than females to drop out at the six-month follow-up $(\mathrm{p}=.01)$. In addition, subjects who were retained for the six-month follow-up reported fewer initial symptoms $(\mathrm{p}=.03)$ and peritraumatic dissociative experiences $(\mathrm{p}=.05)$ than those who 
were not retained. No differences were found between participants who remained in the study and those who dropped out on any other variables. Due to missing data, sample sizes of analyses ranged from 190 to 245 at the six-week follow-up and 150 to 191 at the six-month follow-up.

\section{Procedure}

Approximately 48 hours (range $=1.5$ hours to 19 days) after admission to the hospital a trauma nurse administered the Mini-Mental State Exam (Folstein, Folstein \& McHugh, 1975) to determine the patient's ability to give informed consent. Eligible patients were then approached by a researcher who described the study, obtained consent, and collected demographic information. Questionnaires were administered to collect information about acute responses to the accident including the Impact of Event Scale Revised (IES-R; Weiss \& Marmar, 1997), Peritraumatic Dissociative Experiences Questionnaire (PDEQ; Marmar, Weiss \& Metzler, 1997), Pearlin Mastery Scale (Pearlin \& Schooler, 1978), and a question relating to perceived life threat. The injury severity score (ISS; Baker, O’Neill, Haddon \& Long, 1974) was recorded from medical charts. At the six-week and six-month follow-ups, master's level graduate students administered the Clinician Administered PTSD Scale (CAPS; Blake et al., 1995) and the Structured Clinical Interview for DSM-IV (SCID; First, Gibbon, Spitzer \& Williams, 1996) in the participants' homes to evaluate PTSD symptoms and concurrent depression diagnosis respectively. 


\section{Measures}

\section{Initial Posttraumatic Stress Symptoms}

The Revised Impact of Event Scale (IES-R; Weiss \& Marmar, 1997) is a 22-item self-report questionnaire designed to assess intrusive, avoidant and hyperarousal symptoms following a stressful event. Participants read statements about thoughts and behaviors related to the accident that they may have experienced and were asked to rate how true the statements were on a scale from 0 (not at all) to 4 (extremely). Example statements include “I thought about it when I didn’t want to” (intrusive), “I stayed away from reminders about it” (avoidant) and “I was jumpy and easily startled” (hyperarousal). Twenty-six participants only partially completed the questionnaire. In cases where 2 or fewer items were missing per subscale, missing values were imputed using the individual subscale mean. Chronbach’s alpha for the present study was .90.

\section{Peritraumatic Dissociation}

The Peritraumatic Dissociative Experiences Questionnaire (PDEQ: Marmar et al., 1997) was used to assess an individual's experiences during and immediately following the accident. Participants were asked to respond to a series of ten statements about different dissociative experiences such as "What was happening seemed unreal to me, like I was in a dream or watching a movie or play" or "I felt disoriented, that is, there were moments when I felt uncertain about where I was or what time it was”. Each item was rated on a scale from 1 (not at all true) to 5 (extremely true) and summed to create a total dissociative experiences score (possible range of 10-50). Sixteen participants had 3 
or fewer missing values in this measure which were imputed with the individual's mean score. Reliability was acceptable (Chronbach’s alpha=.78).

Mastery. The Pearlin Mastery Scale (Pearlin \& Schooler, 1978) examines to what extent people feel they have control in their lives. Participants were asked to respond to seven statements such as “There is little I can do to change many of the important things in my life” and rate them on a scale from 1 (strongly agree) to 4 (strongly disagree). Items were summed to create a total mastery score. Scores have a possible range of 7 (low mastery) to 28 (high mastery). Four participants were missing a single item on this measure which was imputed with the individual mean score. Internal consistency for this measure was acceptable (Chronbach’s alpha=.68)

Perceived threat. To assess perception of life threat during the accident, participants were asked to answer the question "To what extent did you fear for your own life during the accident?” on a scale of 1 (not at all) to 7 (a lot).

Injury Severity. The injury severity score (ISS; Baker et al., 1974) is frequently utilized in hospitals and medical centers to evaluate treatment and recovery considerations and risk for mortality. Computing the ISS involves recording the extent of injury to seven regions of the body on a scale from 0 to 6 , with higher numbers representing more serious injury. The ISS is derived by calculating the sum of squares of the three regions with the highest ratings. 
PTSD Symptoms. The Clinician Administered PTSD Scale (CAPS; Blake et al., 1995) is a structured clinical interview that measures the frequency and intensity of PTSD symptoms. Master’s level clinical psychology graduate students conducted the interview regarding symptoms that had resulted from the MVA in the past month. This measure provides both a continuous symptom score and a diagnosis. Chronbach's alpha was .91 at six weeks and .92 at six months.

Depression. Diagnosis of major depression was determined through the Structured Clinical Interview for DSM-IV (SCID; First et al., 1996). The major depression module evaluates ten depressive symptoms and impairments in functioning, and rules out depression due to organic disease or recent bereavement. Interviews were conducted by master's level clinical psychology graduate students, and a diagnosis of major depression was applied if more than five symptoms were endorsed that could not be accounted for by health or bereavement reasons.

\section{Data Analyses}

One way analyses of variance (ANOVAs) were conducted to examine gender differences in initial posttraumatic symptoms, mastery, dissociation, perceived life threat, PTSD symptoms and demographic variables. Bivariate correlations were used to evaluate associations among the variables of interest.

Based on these correlations, mediation models were used to evaluate the role of peritraumatic factors as explanations for gender differences in PTSD symptoms six weeks and six months post-MVA. Mediation analyses followed the guidelines of Baron 
and Kenny (1986) which specify that significant relationships must exist between 1) the predictor and the mediator; 2) the predictor and the outcome; and 3) the mediator and the outcome after controlling for the predictor. Mediation is present if the standardized regression coefficient for the relationship between the predictor and the outcome is no longer significant once the mediator is added to the model. (Baron \& Kenny, 1986) The Sobel test was used to confirm the significance of the mediation. 


\section{CHAPTER 3}

\section{RESULTS}

\section{One Way ANOVAs}

One way ANOVAs were used to examine gender differences in the variables of interest. Results suggested that females reported significantly more PTSD symptoms at both six weeks $(\mathrm{F}(1,246)=16.65, \mathrm{p}<.001)$ and six months post-MVA $(\mathrm{F}(1,192)=20.26$, $\mathrm{p}<.001)$. In addition, females reported greater levels of acute PTSD symptoms $(\mathrm{F}(1,342)=4.99, \mathrm{p}=.03)$ and perceived life threat $(\mathrm{F}(1,268)=7.04, \mathrm{p}=.01)$. Males reported higher income $(\mathrm{F}(1,321)=14.04, \mathrm{p}<.001)$ and mastery as compared to females $(\mathrm{F}(1,350)=7.43, \mathrm{p}=.01)$. Peritraumatic dissociation showed only marginally significant gender differences $(\mathrm{p}=.08)$. Thus, dissociation did not meet Baron and Kenny's (1986) recommendations and was not tested as a mediator. No gender differences existed in current age $(\mathrm{p}=.31)$ or injury severity score $(\mathrm{p}=.81)$. Means, standard deviations and results of one way ANOVAs are displayed in Table 1.

\section{Bivariate Correlations}

Pearson product moment coefficients were used to evaluate associations between PTSD symptoms, acute responses to trauma and demographic variables. Correlations are displayed in Table 2. Results revealed that PTSD symptoms were positively correlated 
Table 1

Means, Standard Deviations and Results of One Way ANOVAs examining gender differences in peritraumatic responses, demographic variables and PTSD symptoms.

\begin{tabular}{|c|c|c|c|c|c|}
\hline & $\begin{array}{c}\text { Total sample } \\
{[\mathrm{M}(\mathrm{SD})]}\end{array}$ & $\begin{array}{c}\text { Males } \\
{[\mathrm{M}(\mathrm{SD})]}\end{array}$ & $\begin{array}{l}\text { Females } \\
{[\mathrm{M}(\mathrm{SD})]}\end{array}$ & $\mathrm{F}$ & $\begin{array}{c}\text { Cohen's } \\
\text { D }\end{array}$ \\
\hline \multicolumn{6}{|l|}{ In-hospital (n=357) } \\
\hline $\begin{array}{l}\text { Initial PTSD } \\
\text { symptoms }\end{array}$ & $26.79(17.41)$ & $25.08(16.60)$ & $29.32(18.32)$ & $4.99 *$ & .24 \\
\hline $\begin{array}{l}\text { Peritraumatic' } \\
\text { dissociation }\end{array}$ & $23.20(8.42)$ & $22.49(8.34)$ & $24.26(8.45)$ & 3.08 & .21 \\
\hline Mastery & $22.48(3.96)$ & $22.97(3.95)$ & $21.82(3.86)$ & $7.43 * *$ & .29 \\
\hline $\begin{array}{l}\text { Perceived life } \\
\text { threat }\end{array}$ & $3.73(2.64)$ & $3.37(2.63)$ & $4.22(2.60)$ & $7.04 * *$ & .32 \\
\hline Injury severity & $7.27(5.66)$ & $7.35(5.31)$ & $7.20(6.15)$ & .06 & .03 \\
\hline Income & $2.83(2.14)$ & $3.21(2.20)$ & $2.32(1.95)$ & $14.04 * * *$ & .43 \\
\hline Age & $38.60(16.20)$ & $37.86(15.70)$ & $39.65(16.87)$ & 1.05 & .11 \\
\hline$\frac{\frac{\text { Six-week }}{\text { follow-up }}}{(n=249)}$ & & & & & \\
\hline PTSD symptoms & $27.71(22.92)$ & $22.61(17.81)$ & $34.22(26.83)$ & $16.65 * * *$ & .52 \\
\hline$\frac{\frac{\text { Six-month }}{\text { follow-up }}}{(n=194)}$ & & & & & \\
\hline PTSD symptoms & $21.86(20.80)$ & $15.71(15.50)$ & $28.58(23.74)$ & $20.26 * * *$ & .66 \\
\hline
\end{tabular}


Table 2

Bivariate correlations among peritraumatic responses, demographic variables and PTSD symptoms

\begin{tabular}{|c|c|c|c|c|c|c|c|c|c|c|c|}
\hline Variables & 1 & 2 & 3 & 4 & 5 & 6 & 7 & 8 & 9 & 10 & 11 \\
\hline $\begin{array}{l}\text { 1. Initial PTSD } \\
\text { Symptoms }\end{array}$ & - & & & & & & & & & & \\
\hline $\begin{array}{l}\text { 2. Peritraumatic } \\
\text { dissociation }\end{array}$ & $.48 * * *$ & - & & & & & & & & & \\
\hline 3. Mastery & $-.11 *$ & $-.15^{*}$ & - & & & & & & & & \\
\hline $\begin{array}{l}\text { 4. Perceived } \\
\text { life threat }\end{array}$ & $.22 * * *$ & .09 & -.01 & - & & & & & & & \\
\hline 5. Injury severity & -.07 & .05 & -.03 & .03 & - & & & & & & \\
\hline 6. Income & $-.18 * *$ & $-.13 *$ & $.17 * *$ & $-.15^{*}$ & .02 & - & & & & & \\
\hline 7. Age & $-.23 * * *$ & $-.22 * * *$ & $-.11 *$ & $-.14^{*}$ & .04 & $.29 * * *$ & - & & & & \\
\hline $\begin{array}{l}\text { 8. } 6 \text { week PTSD } \\
\text { symptoms }\end{array}$ & $.46^{* * *}$ & $.29 * * *$ & $-.13^{*}$ & .06 & -.03 & $-.14 *$ & $-.15^{*}$ & - & & & \\
\hline $\begin{array}{l}\text { 9. } 6 \text { week } \\
\text { depression }\end{array}$ & $.16^{*}$ & .13 & -.09 & .00 & .06 & -.11 & .01 & $.55 * * *$ & - & & \\
\hline $\begin{array}{ll}\text { 10. } & 6 \text { month } \\
& \text { PTSD } \\
\text { symptoms }\end{array}$ & $.47 * * *$ & $.38 * * *$ & $-.22 * *$ & .15 & -.01 & $-.20 * *$ & -.11 & $.71 * * *$ & $.51 * * *$ & - & \\
\hline $\begin{array}{l}\text { 11. } 6 \text { month } \\
\text { depression }\end{array}$ & $.26 * * *$ & $.19^{*}$ & $-.30^{* *}$ & -.11 & -.05 & -.11 & .02 & $.49 * * *$ & $.42 * * *$ & $.56 * * *$ & - \\
\hline
\end{tabular}


with acute symptoms (six weeks $\mathrm{r}=.46, \mathrm{p}<.001$; six months $\mathrm{r}=.47, \mathrm{p}<.001$ ) and peritraumatic dissociation ( six weeks $\mathrm{r}=.29, \mathrm{p}<.001$; six months $\mathrm{r}=.38, \mathrm{p}<.001$ ), suggesting that these acute responses were associated with increased PTSD symptoms both six weeks and six months post-MVA. Mastery, however, was negatively associated with six-week $(\mathrm{r}=-.13, \mathrm{p}=.04)$ and six-month $(\mathrm{r}=-.22, \mathrm{p}=.002)$ PTSD symptoms, suggesting that victims with a greater sense of mastery over their situation developed fewer PTSD symptoms. Current age was the only demographic variable to correlate significantly with PTSD symptoms at the six-week follow-up $(r=-.15, p=.02)$, such that younger victims reported more PTSD symptoms. Perceived life threat was not significantly correlated with PTSD symptoms (six weeks $\mathrm{p}=.42$, six months $\mathrm{p}=.07$ ), and therefore was not tested with mediation models.

Passenger vs. driver status was examined as a potential covariate for the mastery model. A chi square analysis failed to find significant gender differences in passenger vs. driver status during the accident $(\mathrm{p}=.66)$, and a one way ANOVA showed it was also not associated with mastery $(\mathrm{p}=.09)$. Therefore, no covariates were used in the mediation models.

\section{Mediation Analyses}

Mediation analyses were conducted using linear regression to test acute symptoms and mastery as mediators of the relationship between gender and PTSD symptoms. A hierarchical linear regression was conducted for each mediator and PTSD outcome, resulting in four models. Gender was entered in Step 1 as the predictor and the mediator 
was entered in Step 2. Six-week or six-month PTSD symptom scores served as the outcome variable. Because there is some symptom overlap between PTSD and depression, it is unclear whether depression should be controlled in PTSD models. To address this concern, analyses were repeated excluding participants with a diagnosis of major depression concurrent with their PTSD symptoms.

Regressions examining initial symptoms as a mediator between gender and development of later PTSD symptoms revealed a significant positive association between gender and acute symptoms (six weeks $\beta=.13, p=.05$; six months $\beta=.16, p=.03$ ) and between gender and later PTSD symptoms ( $\operatorname{six}$ weeks $\beta=.25, \mathrm{p}<.001$; six months $\beta=.29$, $\mathrm{p}<.001$ ), suggesting that female gender is associated with higher levels of PTSD symptoms immediately following the MVA, as well as six weeks and six months later. In addition, acute symptoms (six weeks $\beta=.44, \mathrm{p}<.001$; six months $\beta=.44, \mathrm{p}<.001$ ) significantly predicted development of later symptoms after controlling for gender. The standardized regression coefficient for gender was reduced from .25 to .20 when acute symptoms were added to the six weeks model and .29 to .22 in the six-month model. However, gender ( $\operatorname{six}$ weeks $\beta=.20, p=.001$; six months $\beta=.22, p=.001$ ) continued to significantly predict PTSD symptoms after initial symptoms were added to the model, suggesting partial mediation. The Sobel test confirmed marginal significance of the six week mediation $(\mathrm{z}=1.88, \mathrm{p}=.06)$ and significance of the six month mediation $(\mathrm{z}=2.09$, $\mathrm{p}=.04$ ). These results are displayed in Figure 1. Acute symptom clusters (intrusive, avoidant and hyperarousal symptoms) were also examined separately to determine 

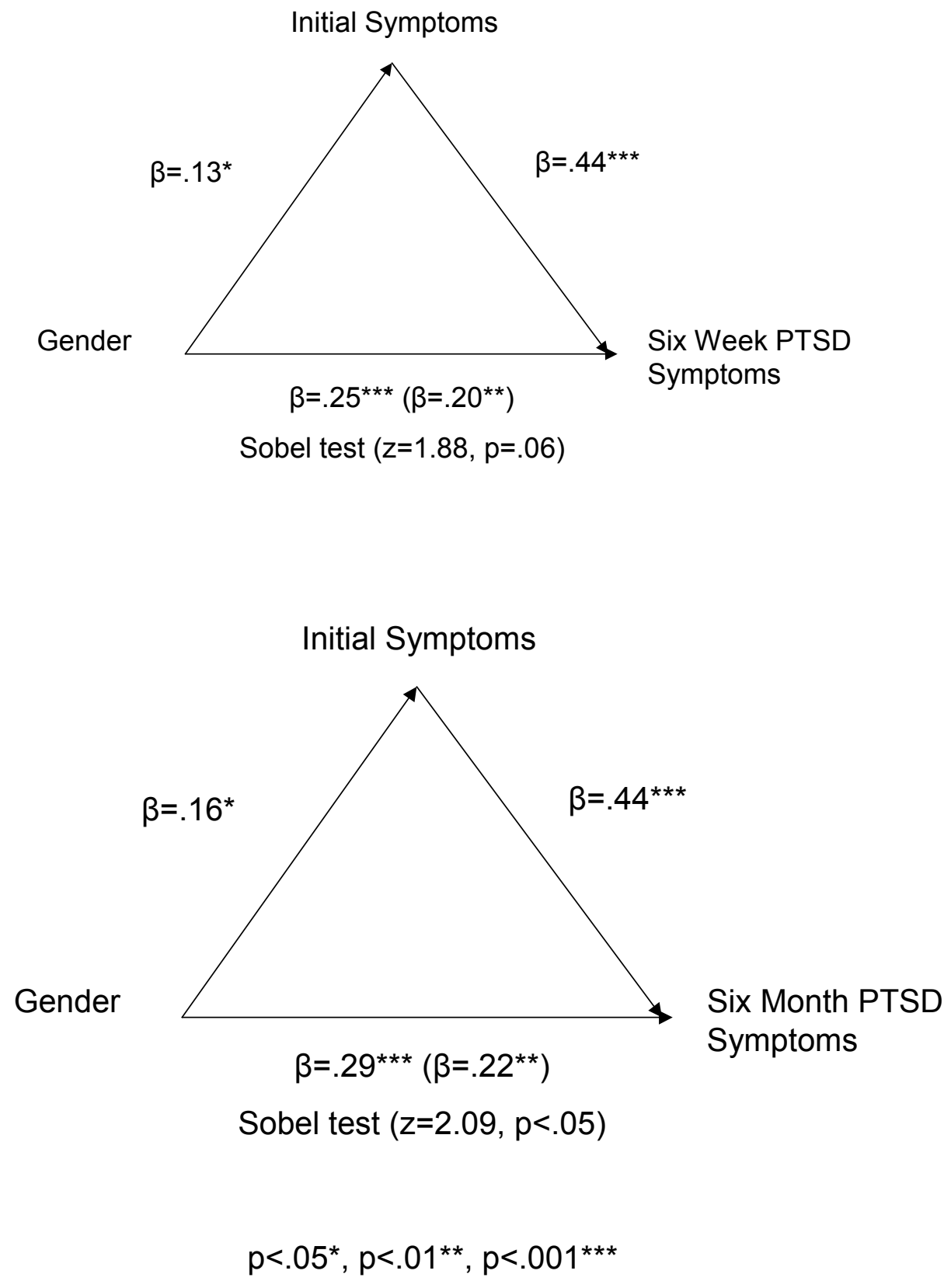

Figure 1. Results of mediation models examining gender, initial symptoms and development of PTSD symptoms six weeks and six months post-MVA. 
whether certain symptom clusters were responsible for the gender differences in later PTSD symptoms. Results were consistent across all symptom clusters and total symptom scores.

Mastery was examined as a second possible mediator in the relationship between gender and PTSD symptom development. Results of regression analyses suggest that females reported a lower sense of mastery ( $\operatorname{six}$ weeks $\beta=-.14, p=.03$; six months $\beta=-.12$, $\mathrm{p}=.10$ ) and more PTSD symptoms ( $\operatorname{six}$ weeks $\beta=.25, \mathrm{p}<.001$; six month $\beta=.30, \mathrm{p}<.001$ ) than males. After controlling for gender, mastery contributed significantly to the variance in PTSD symptoms (six weeks $\beta=-.16, p=.09$; six months $\beta=-.19, p=.01$ ) and produced a very small reduction in beta of gender. While the results for mastery were stronger at six months, mastery was not supported as a mediator of the relationship between gender and PTSD symptom development at either time point. These results are displayed in Figure 2. Excluding depressed participants did not impact the results of the mediation models. 


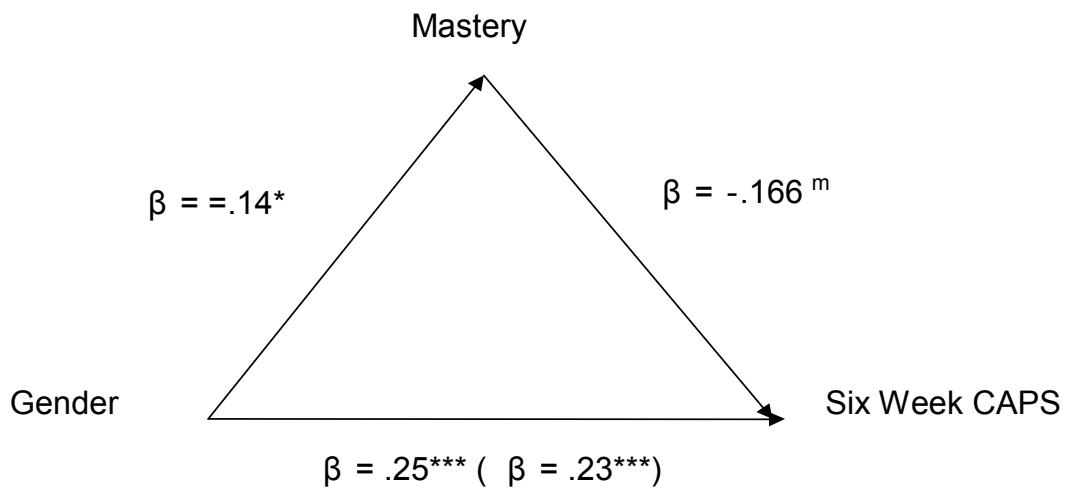

Sobel test $(z=1.34, p=.18)$

$p<.10 \mathrm{~m}, p<.05^{\star}, p<.01^{\star *}, p<.001^{* \star *}$

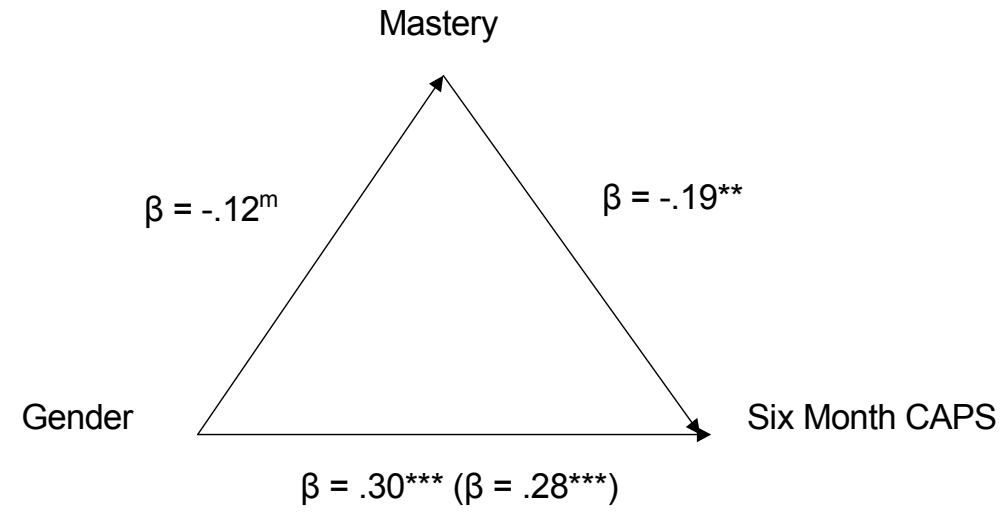

Sobel test $(z=1.44, p=.18)$

$p<.10^{m}, p<.05^{*}, p<.01^{* *}, p<.001^{* * *}$

Figure 2. Results of mediartion models examining gender, mastery and development of PTSD symptoms six weeks and six months post-MVA. 


\section{CHAPTER 4}

\section{DISCUSSION}

The aim of the present study was to examine acute and peritraumatic factors hypothesized to contribute to gender differences in PTSD symptoms following a MVA. Surprisingly, perceived threat, mastery and peritraumatic dissociation were not supported as explanatory mechanisms of gender differences in PTSD. However, results did provide support for the predictive ability of initial PTSD symptoms reported an average of 48 hours after the accident. Mediation analyses suggested that the tendency for females to develop more PTSD symptoms six weeks and six months after the accident could be partially accounted for by gender differences in initial PTSD symptom responses to the trauma. It is interesting to note that these gender differences were apparent in the immediate aftermath of a trauma, rather than appearing gradually over time. However, as it is unclear why these symptoms initially develop differently in men and women, the question of gender differences in PTSD symptom development is still somewhat unanswered. It may be that similar factors underlie sex-specific risk for both acute and chronic PTSD symptoms.

Future investigation of gender differences in PTSD should focus on additional characteristics of both trauma and victim. A number of biological and cognitive mechanisms have been put forward as potential explanations for gender differences in 
PTSD symptoms. Several biological alterations have been noted as possible markers for PTSD risk and maintenance including increased sympathetic nervous system activation (i.e. Pitman, Shalev \& Orr., 2000) and HPA axis dysregulation leading to lower levels of cortisol (i.e. Delahanty et al., 2003). However, the lack of empirical evidence examining gender differences in these biological mechanisms makes it difficult to draw any conclusions regarding gender and PTSD. A more cognitive perspective may argue that more emphasis should be placed on individuals' appraisals of their symptoms rather than the symptoms themselves. Ehlers and Clark (2000) propose that a trauma victim who views their symptoms as part of a natural healing process will likely have a very different experience than a victim who views those same symptoms as a sign that they are going mad. Evidence has empirically supported symptom appraisal as a strong predictor of PTSD (Dumnore, Clark \& Ehlers, 2001; Ehlers et al., 1998), and further examination of differential symptom appraisals by males and females may help explain differences in PTSD.

Furthermore, future studies should focus on prospective designs in a variety of samples. There are many other factors to consider that may play a role in creating sexspecific risk for PTSD. Characteristics present in trauma victims before the trauma should be considered, including prior trauma history, age at current and prior traumatization and history of family and individual psychopathology. In addition to the acute factors evaluated in the present study, other peritraumatic factors such as cognitive appraisals of self, event and symptoms should be examined along with biological markers and additional life stressors. In the months and years following the trauma, examination 
of adjustment, coping and social support may also help improve our understanding of gender differences in PTSD risk and maintenance.

The present study suffered from two primary limitations. The sample is entirely victims of MVAs, and therefore our findings may not generalize to other traumatized populations. In addition, as is often the case with accident victims, symptom severity was low in both males and females. Research in samples with a wider range of symptoms and higher rates of diagnostic levels of PTSD may produce different results regarding gender differences in PTSD. Despite these limitations, this study took a necessary first step toward systematically examining explanatory mechanisms of gender differences in PTSD. Investigation of a wider range of biological, cognitive and psychosocial factors in a variety of trauma populations will further our understanding of the underlying cause of female vulnerability to PTSD. 


\section{REFERENCES}

American Psychiatric Association. (1994). DSM-IV: Diagnostic and statistical manual of mental disorders (4 ${ }^{\text {th }}$ ed.). Washington, DC: American Psychiatric Association.

Baker, S.P., O’Neill, B., Haddon, W. \& Long, W.B. (1974). The injury severity score: a method for describing patients with multiple injuries and evaluating emergency care. Journal of Trauma, 14, 187-196.

Baron, R.M. \& Kenny, D.A. (1986). The moderator-mediator variable distinction in social psychological research: Conceptual, strategic and statistical considerations. Journal of Personality and Social Psychology, 51(6), 1173-1182.

Benight, C.C. \& Bandura, A. (2004). Social cognitive theory of posttraumatic recovery: the role of perceived self-efficacy. Behaviour Research and Therapy, 42, 1129 1148.

Benight, C.C., Freyaldenhoven, R., Hughes, J., Ruiz, J.M., Zoesche, T.A. \& Lovallo, W. (2000). Coping self-efficacy and psychological distress following the Oklahoma city bombing: A longitudinal analysis. Journal of Applied Social Psychology, 30, 1331-1344.

Benight, C.C., Ironson, G. \& Durham, B. (1999). Psychometric properties of a hurricane coping self-efficacy measure. Journal of Traumatic Stress, 12, 397-386. 
Bernat, J.A., Ronfeldt, H.M., Calhoun, K.S. \& Arias, I. (1998). Prevalence of traumatic events and peritraumatic predictors of posttraumatic stress symptoms in a nonclinical sample of college students. Journal of Traumatic Stress, 11, 645-665.

Birmes, P.J., Brunet, A., Coppin-Calmes, D., Arbus, C., Coppin, D., Charlet, J., Vinnemann, N., Juchet, H., Lauque, D. \& Schmitt, L. (2005). Symptoms of peritraumatic and acute traumatic stress among victims of an industrial disaster. Psychiatric Services, 56(1), 93-95.

Blake, D.D., Weathers, F.W., Nagy, L.M., Kaloupek, D.G., Gusman, F.D., Charney, D.S., \& Keane, T.M. (1995). The development of a clinician-administered PTSD scale. Journal of Traumatic Stress, 8(1), 75-90.

Blanchard, E.B., Hickling, E.J., Mitnick, N., Taylor, A.E., Loos, W.R. \&Buckley, T.C. (1995). The impact of severity of physical injury and perception of life threat in the development of post-traumatic stress disorder in motor vehicle accident victims. Behaviour Research and Therapy, 33(5), 529-534.

Breslau, N., Kessler, R.C., Chilcoat, H.D., Schultz, L.R., Davis, G.C. \& Andreski, P. (1998). Trauma and posttraumatic stress disorder in the community: the 1996 Detroit Area Survey of Trauma. Archives of General Psychiatry, 55, 626-632. Brewin, C.R., Andrews, B., Rose, S. \& Kirk, M. (1999). Acute stress disorder and posttraumatic stress disorder in victims of violent crime. American Journal of Psychiatry, 156, 360-365.

Bryant, R. (2007). Does dissociation further our understanding of PTSD? Journal of Anxiety Disorders, 21, 183-191. 
Bryant, R. \& Harvey, A. (1995). Avoidant coping style and post-traumatic stress following motor vehicle accidents. Behaviour Research and Therapy, 33(6), 631-635.

Bryant, R.A. \& Harvey, A.G. (1996). Initial posttraumatic stress responses following motor vehicle accidents. Journal of Traumatic Stress, 9, 223-234.

Bryant, R.A. \& Harvey, A.G. (2003). Gender differences in the relationship between acute stress disorder and posttraumatic stress disorder following motor vehicle accidents. Australian and New Zealand Journal of Psychiatry, 37, 226-229.

Cardeña, E. \& Spiegel, D. (1993). Dissociative reactions to the San Francisco Bay Area earthquake of 1989. American Journal of Psychiatry, 150, 474-478.

Cassidy, G.L. \& Davies, L. (2003). Explaining gender differences in mastery among married parents. Social Psychology Quarterly, 66(1), 48-61.

Classen, C., Koopman, C., Hales, R. \& Spiegel, D. (1998). Acute stress disorder as a predictor of posttraumatic stress symptoms. American Journal of Psychiatry, 155(5), 620-624.

Curran, P.S., Bell, P., Murray, A., Loughrey, G., Roddy, R. \& Rocke, L.G. (1990). Psychological consequences of the Enniskillen bombing. British Journal of Psychiatry, 156, 479-482.

Delahanty, D.L., Raimonde, A.J., Spoonster, E. \& Cullado, M. (2003). Injury severity, prior trauma history, urinary cortisol levels, and acute PTSD in motor vehicle accident victims. Anxiety Disorders, 17, 149-164. 
Dunmore, E., Clark, D.M. \& Ehlers, A. (1999). Cognitive factors involved in the onset and maintenance of posttraumatic stress disorder (PTSD) after physical or sexual assault. Behaviour Research and Therapy, 37, 809-879.

Dunmore, E., Clark, D.M. \& Ehlers, A. (2001). A prospective investigation of the role of cognitive factors in persistent posttraumatic stress disorder (PTSD) after physical or sexual assault. Behaviour Research and Therapy, 39, 1063-1084.

Ehlers, A., Mayou, R.A. \& Bryant, B. (1998). Psychological predictors of chronic posttraumatic stress disorder after motor vehicle accidents. Journal of Abnormal Psychology, 107(3), 508-519.

Ehlers, A. \& Clark, D.M. (2000). A cognitive model of posttraumatic stress disorder. Behaviour Research and Therapy, 38, 319-345.

Elkilt, A. (2002). Acute stress disorder in victims of robbery and victims of assault. Journal of Interpersonal Violence, 17(8), 872-887

Feinstein, A. \& Dolan, R. (1991). Predictors of posttraumatic stress disorder following physical trauma: An examination of the stressor criterion. Psychological Medicine, 21, 85-91.

First, M.B., Gibbon, M., Spitzer, R.L. \& Williams, J.B.W. (1996). User's guide for the Structured Clinical Interview for DSM-IV Axis I Disorders - research version (SCID-I, Version 2.0, February 1996 FINAL Version).

Folstein, M.F., Folstein, S.E. \& McHugh, P.R. (1975). Mini-mental state: A practical method for grading the cognitive state of patients for the clinician. Journal of Psychiatric Research, 12, 189-198. 
Frazier, P., Berman, M. \& Steward, J. (2002). Perceived control and posttraumatic stress: A temporal model. Applied and Preventive Psychology, 10, 207-223.

Freuh, B.C., Turner, S.M., Beidel, D.C., Mirabella, R.F. \& Jones, W.J. (1996). Trauma management therapy: A preliminary evaluation of a multicomponent behavioral treatment for chronic combat-related PTSD. Behaviour Research and Therapy, 34, 533-543.

Fullerton, C.S., Ursano, R.J., Epstein, R.S., Crowley, B., Vance, K., Kao, T., Dougall, A. \& Baum, A. (2001). Gender differences in posttraumatic stress disorder after motor vehicle accidents. American Journal of Psychiatry, 158, 1486-1491.

Grieger, T.A., Fullerton, C.S. \& Ursano, R.J. (2003). Posttraumatic stress disorder, alcohol use and perceived safety after the terrorist attack on the Pentagon. Psychiatric Services, 54, 1380-1382.

Harvey, A.G. \& Bryant, R.A. (1998). Relationship of acute stress disorder and posttraumatic stress disorder following motor vehicle accidents. Journal of Consulting and Clinical Psychology, 66, 507-512.

Harvey, A.G. \& Bryant, R.A. (1999). Relationship of acute stress disorder and posttraumatic stress disorder: A two year prospective study. Journal of Consulting and Clinical Psychology, 67, 985-988.

Karanci, N.A., Alkan, N., Aksit, B., Sucuoglu, H. \& Balta, E. (1999). Gender differences in psychological distress, coping, social support and related variables following the 1995 Dinar (Turkey) earthquake. North American Journal of Psychology, 1(2), 189-204. 
Kessler, R.C., Sonnega, A., Bromet, E., Hughes, M. \& Nelson, C.B. (1995).

Posttraumatic stress disorder in the National Comorbidity Survey. Archives of General Psychiatry, 52, 1048-1060.

Kilpatrick, D.G., Saunders, B.E., Amick-McMullan, A., Best, C.L., Veronen, L.J. \& Resnick, H.S. (1989). Victim and crime factors associated with the development of crime-related post-traumatic stress disorder. Behavior Therapy, 20, 199-214.

Koopman, C., Classen, C. \& Speigel, D. (1994). Predictors of posttraumatic stress symptoms among survivors of the Oklahoma/Berkeley, Calif., firestorm. American Journal of Psychiatry, 151, 888-894.

Lawyer, S.R., Resnick, H.S., Galea, S., Ahern, J., Kilpatrick, D.G. \& Vlahov, D. (2006). Predictors of peritraumatic reactions and PTSD following the September $11^{\text {th }}$ terrorist attacks. Psychiatry, 69(2), 130-141.

Marmar, C.R., Weiss, D.S. \& Metzler, T.J. (1997). The peritraumatic dissociative experiences questionnaire. In J.P. Wilson \& T.M. Keane (Eds.), Assessing psychological trauma and PTSD. New York: Guilford Press.

Murphy, S.A. (1987). Self-efficacy and social support: Mediators of stress on mental health following a natural disaster. Western Journal of Nursing Research, 9, 58 86.

Nixon, R.D.V. \& Bryant, R.A. (2005). Are negative cognitions associated with severe acute trauma responses? Behaviour Change, 22(1), 22-28.

Nolen-Hoeksema, S., Larson, J. \& Grayson, C. (1999). Gender differences in depressive symptoms. Journal of Personality and Social Psychology, 77(5), 1061-1072. 
North, C.S., Smith, E.M. \& Spitznagel, E.L. (1994). Posttraumatic stress disorder in survivors of a mass shooting. American Journal of Psychiatry, 151, 82-88.

Norris, F.H. (1992). Epidemiology of trauma: Frequency and impact of different potentially traumatic events on different groups. Journal of Consulting and Clinical Psychology, 60, 409-418.

Norris, F.H., Foster, J.D. \& Weisshaar, D.L. (2002). The epidemiology of sex differences in PTSD across developmental, societal and research contexts. In R. Kimerling, P. Ouimette \& J. Wolfe (Eds.), Gender and PTSD. New York: Guilford Press.

Olff, M., Langeland, W., Draijer, N. \& Gersons, B.P. (2007). Gender differences in posttraumatic stress disorder. Psychological Bulletin, 133(2), 183-204.

Ozer, E.J., Best, S.R., Lipsey, T.L. \& Weiss, D.S. (2003). Predictors of posttraumatic stress disorder and symptoms in adults: A meta-analysis. Psychological Bulletin, 129(1), 52-73.

Ozer, E.M. \& Bandura, A. (1990). Mechanisms governing empowerment efforts: A self efficacy analysis. Journal of Personality and Social Psychology, 58, 472-486.

Pearlin, L.I. \& Schooler, C. (1978). The structure of coping. Journal of Health and Social Behavior, 19, 2-21.

Perry, S., Difede, J., Musngi, G., Frances, A.J. \& Jacobsberg, L. (1992). Predictors of posttraumatic stress disorder after burn injury. American Journal of Psychiatry, 149(7), 931-935. 
Pitman, R.K., Shalev, A.Y. \& Orr, S.P. (2000). Posttraumatic stress disorder: Emotion, conditioning and memory. In M.D. Corbetta \& M. Gazzaniga (Eds.) The New Cognitive Neurosciences, $2^{\text {nd }}$ Ed. New York: Plenum Press.

Punamaki, R., Komproe, I.H., Qouta, S., Elmasri, M. \& de Iong, J.T.V.M. (2005). The role of peritraumatic dissociation and gender in the association between trauma and mental health in a Palestinian community sample. American Journal of Psychiatry, 162(3), 545-551.

Richmond, T.S. \& Kaunder, D. (2000). Predictors of psychological distress following serious injury. Journal of Traumatic Stress, 13(4), 681-692.

Riggs, D.S., Rothbaum, B.O. \& Foa, E.B. (1995). A prospective examination of symptoms of posttraumatic stress disorder in victims of nonsexual assault. Journal of Interpersonal Violence, 10, 201-213.

Rothbaum, B.O., Foa, E.B., Riggs, D.S., Murdock, T. \& Walsh, W. (1992). A prospective examination of posttraumatic stress disorder in rape victims. Journal of Traumatic Stress, 5, 455-475.

Rubinstein, G. (2004). Locus of control and helplessness: Gender differences among bereaved parents. Death Studies, 28, 211-223.

Shalev, A.Y., Freedman, S., Peri, T., Brandes, D., Sahar, T., Orr, S.P. \& Pitman, R.K. (1998). Prospective study of posttraumatic stress disorder and depression following trauma. American Journal of Psychiatry, 155, 630-637. 
Solomon, Z., Gelkopf, M. \& Bleich, A. (2005). Is terror gender-blind? Gender differences in reaction to terror events. Social Psychiatry and Psychiatric Epidemiology, 40, 947-954.

Tolin, D.F. \& Foa, E.B. (2006). Sex differences in trauma and posttraumatic stress disorder: A quantitative review of 25 years of research. Psychological Bulletin, 132(6), 959-992.

Ursano, R.J., Fullerton, C.S., Epstein, R.S., Crowley, B., Vance, K., Kao, T.C. \& Baum, A.S. (1999). Peritraumatic dissociation and posttraumatic stress disorder following motor vehicle accidents. American Journal of Psychiatry, 156, 1808-1810.

Weiss, D.S. \& Marmar, C.S. (1997). The impact of even scale - revised. In J.P. Wilson \& T.M. Keane (Eds.), Assessing psychological trauma and PTSD. New York: Guilford Press. 
APPENDIX A

\section{CONSENT FORMS}


Project Title: Peritraumatic psychophysiological predictors of well-being following motor vehicle accidents

Investigators: Douglas L. Delahanty, $\mathrm{PhD}$, Kent State University

Jay Raimonde, MD, Summa Health System

Farid Muakkassa, MD, Akron General Hospital

INTRODUCTION: You are being asked to participate as one of approximately 400 subjects in a research study examining peoples' responses to motor vehicle accidents. All subjects will have been involved in a motor vehicle accident and will have been seen by a Summa Health System or Akron General Hospital trauma team due to injuries suffered in the accident. We have previously found that initial thoughts, feelings, behaviors, and physiological responses can predict later well-being, and we would like to examine your initial and later responses to your specific accident.

YOUR PARTICIPATION: If you decide to take part in this experiment, one of the members of our research team will ask you a few questions now (this will take about $15 \mathrm{~min}$ ), call you and ask you a few questions in 2 weeks (about 25min), and meet with you 6 weeks after your accident, and then 3, 6 and 12 months after your accident. Each of these meetings will last approximately 1 - 2 hours and will be scheduled at a convenient time in your home. During the first assessment we will ask you to fill out a few questionnaires and we will take two- $60 \mathrm{ml}$ samples of your urine from the urine that the hospital is collecting. In addition, we will take a small sample of plasma from blood that has already been collected by the hospital. The urine and plasma samples will be used to measure levels of hormones in your body -the samples will not be used for any alcohol or drug testing. Two weeks after your accident we will call you and ask you a few questions over the phone. At this time we will ask you to provide us with two saliva samples which will also be used only for measuring hormones. During each subsequent assessment we will come to your house and ask you questions about what you remember of your accident. To ensure that we don't miss anything, your answers will be audiotaped. We will also be asking you to fill out a variety of questionnaires and to participate in an interview designed to measure your thoughts, feelings, and reactions to your accident. In addition, at the fourth, fifth, and sixth assessments you will be asked to provide a urine sample (to measure hormone levels), and we will draw one and a half tubes of blood to measure immune and hormone levels. Your blood will be drawn by a person trained to minimize any discomfort, and the amount we take is approximately 7-9 teaspoons. If you are uncomfortable having your blood drawn, you may skip this part of the study. We will also need to look at your medical records to determine what specific injuries you may have suffered in your accident. By signing below, you are giving us permission to look at these records.

BENEFITS: You personally may not receive any direct benefit from your participation in this study. Your participation in this study may enable us to help future victims of motor vehicle accidents.

RISKS: Some of the questions we ask will require you to remember aspects of your accident, and this may lead to increases in distress. The long-term effects of discussing your memories is unknown, but it is possible that some of the questions may provoke stressful memories. In addition, as the long-term effects of early memory recall is unknown, participating in the present study may have no effect on your levels of distress, may lead to longer-lasting distress, or may reduce your levels of distress. Risks associated with having your blood drawn include slight discomfort and bruising at the site.

Subject's initials

Date 
If any part of the study causes you to become distressed (symptoms of distress and/or depression include sleep disruption, concentration problems, changes in appetite, and similar disruptions in normal functioning), please call Dr. Jay Raimonde at (330) 253-5030 for an appropriate referral during office hours. After office hours you can call the Community Support Services in your county using the number we have provided.

CONFIDENTIALITY: All data collected in this study will be kept strictly confidential within the limits of the law. This means that your data will only be revealed if we are subpoenaed by an attorney. Some of the data may contain very sensitive information that could be used in court. The information you provide us with will be identified only by a subject number, and will be examined only by Dr. Delahanty and qualified members of his research team. The only copies of the data will remain in a locked file. After the study, data will be published in scientific journals, but data will not be published in any manner that can identify you.

VOLUNTARY PARTICIPATION: Your participation in this study is voluntary and you may decline to participate in it without loss of any future services or benefits to which you may be entitled. Should you choose to participate, you may voluntarily withdraw from it at any time. By signing this form you are indicating that you have been informed about the research study in which you are agreeing to participate, and have had all of your questions satisfactorily answered. You will receive a copy of this form for your records.

RESEARCH-RELATED INJURIES: You should also be aware that there are no Federal, State or private programs established to provide research subjects with compensation and/or medical treatment or other financial losses due to physical injuries resulting from research procedures such as the one in which you are being asked to participate.

COSTS: You are not responsible for any costs above those of your standard or routine care. Twenty-five dollars at the initial session and each following session (\$150.00 total) will be provided to you to compensate you for your time.

QUESTIONS: If you have any questions now, during or following your participation regarding this study and its associated risks, please contact Douglas L. Delahanty at (330) 672-2395. This project has been approved by Summa Health System and Akron General Medical Center. If you have any questions regarding your rights as a research subject please call the Summa Health System Institutional Review Board, telephone (330) 375-4045 or Lisa Treen at Akron General at 330-344-6084.

SIGNATURE LINES: By signing this form I acknowledge that I have read it, understand it, and have had any questions regarding the risks and benefits of this study satisfactorily answered, and I am voluntarily consenting to participate in this study. Further, I realize that by signing this form I do not waive any of my legal rights.

Date:

Subject Signature:

Date: Researcher Signature:

(Person obtaining consent) 


\section{APPENDIX B}

MEASURES 
Impact of Event Scale - Revised

Sometimes, after a serious accident such as the one you were in, people find themselves having thoughts about the accident that suddenly pop into their heads even when they are not trying to think about the accident. These thoughts are called intrusive thoughts. Please answer the following questions based on any intrusive thoughts you have had about your accident.

\section{Have you experienced intrusive thoughts in the last week?}

$$
\text { Yes No Don't Know }
$$

\section{What do you see/hear/smell/taste while experiencing intrusive thoughts:}

Below is a list of comments made by people after stressful life events. Please check each item, indicating how frequently these comments were true for you SINCE THE ACCIDENT. If they did not occur during that time, please mark the "not at all” column.

Please think of your car accident when filling out this questionnaire.

\begin{tabular}{|l|c|c|c|c|c|}
\hline & $\begin{array}{c}\text { Not at } \\
\text { all }\end{array}$ & $\begin{array}{c}\text { A little } \\
\text { bit }\end{array}$ & $\begin{array}{c}\text { Mod- } \\
\text { erately }\end{array}$ & $\begin{array}{c}\text { Quite a } \\
\text { bit }\end{array}$ & $\begin{array}{c}\text { Extre- } \\
\text { mely }\end{array}$ \\
\hline $\begin{array}{l}\text { 1. } \quad \text { Any reminder brought back feelings } \\
\text { about it }\end{array}$ & 0 & 1 & 2 & 3 & 4 \\
\hline 2. I had trouble staying asleep & 0 & 1 & 2 & 3 & 4 \\
\hline $\begin{array}{l}\text { 3. Other things kept making me think } \\
\text { about it }\end{array}$ & 0 & 1 & 2 & 3 & 4 \\
\hline 4. I felt irritable and angry & 0 & 1 & 2 & 3 & 4 \\
\hline $\begin{array}{l}\text { 5. I avoided letting myself get upset } \\
\text { when I thought about it or was } \\
\text { reminded of it }\end{array}$ & 0 & 1 & 2 & 3 & 4 \\
\hline $\begin{array}{l}\text { 6. I thought about it when I didn't } \\
\text { mean to }\end{array}$ & 0 & 1 & 2 & 3 & 4 \\
\hline $\begin{array}{l}\text { 7. I felt as if it hadn't happened or } \\
\text { wasn't real }\end{array}$ & 0 & 1 & 2 & 3 & 4 \\
\hline $\begin{array}{l}\text { 8. I stayed away from reminders about } \\
\text { it }\end{array}$ & 0 & 1 & 2 & 3 & 4 \\
\hline $\begin{array}{l}\text { 9. Pictures about it popped into my } \\
\text { mind }\end{array}$ & 0 & 1 & 2 & 3 & 4 \\
\hline 10. I was jumpy and easily startled & 0 & 1 & 2 & 3 & 4 \\
\hline 11. I tried not to think about it & 0 & 1 & 2 & 3 & 4 \\
\hline
\end{tabular}




\begin{tabular}{|c|c|c|c|c|c|}
\hline & $\begin{array}{c}\text { Not at } \\
\text { all }\end{array}$ & $\begin{array}{c}\text { A little } \\
\text { bit }\end{array}$ & $\begin{array}{c}\text { Mod- } \\
\text { erately }\end{array}$ & $\begin{array}{l}\text { Quite a } \\
\text { bit }\end{array}$ & $\begin{array}{l}\text { Extre- } \\
\text { mely }\end{array}$ \\
\hline $\begin{array}{l}\text { 12. I was aware that I still had a lot of } \\
\text { feelings about it, but I didn't deal } \\
\text { with them }\end{array}$ & 0 & 1 & 2 & 3 & 4 \\
\hline $\begin{array}{l}\text { 13. My feelings about it were kind of } \\
\text { numb }\end{array}$ & 0 & 1 & 2 & 3 & 4 \\
\hline $\begin{array}{l}\text { 14. I found myself acting or feeling like } \\
\text { I was back at that time }\end{array}$ & 0 & 1 & 2 & 3 & 4 \\
\hline 15. I had trouble falling asleep & 0 & 1 & 2 & 3 & 4 \\
\hline 16. I had waves of strong feelings & 0 & 1 & 2 & 3 & 4 \\
\hline $\begin{array}{l}\text { 17. I tried to remove it from my } \\
\text { memory }\end{array}$ & 0 & 1 & 2 & 3 & 4 \\
\hline 18. I had trouble concentrating & 0 & 1 & 2 & 3 & 4 \\
\hline $\begin{array}{l}\text { 19. Reminders of it caused me to have } \\
\text { physical reactions, such as } \\
\text { sweating, trouble breathing, nausea, } \\
\text { or a pounding heart }\end{array}$ & 0 & 1 & 2 & 3 & 4 \\
\hline 20. I had dreams about it & 0 & 1 & 2 & 3 & 4 \\
\hline 21. I felt watchful and on-guard & 0 & 1 & 2 & 3 & 4 \\
\hline 22. I tried not to talk about it & 0 & 1 & 2 & 3 & 4 \\
\hline
\end{tabular}




\section{Peritraumatic Dissociative Experiences Questionnaire}

INSTRUCTIONS: Please complete the items below by circling the choice that best describes your experiences and reactions during the accident and immediately afterward. If an item does not apply to your experience, please circle "not at all true".

Rate the following items using the following scale:

$\begin{array}{ccccc}1 & 2 & 3 & 4 & 5 \\ \text { Not at all true } & \text { Slightly true } & \text { Somewhat true } & \text { Very true } & \text { Extremely true }\end{array}$

1. I had moments of losing track of what was going on -- I "blanked out" or "spaced out" or in some way felt that I was not part of what was going on.

**At what point from realizing there was going to be an accident to arrival at hospital.

2. I found that I was on "automatic pilot" -- I ended up doing things that I later realized I hadn't actively decided to do.

**At what point from realizing there was going to be an accident to arrival at hospital.

3. My sense of time changed - things seemed to be happening in slow motion.

**At what point from realizing there was going to be an accident to arrival at hospital.

4. What was happening seemed unreal to me, like I was in a dream or watching a movie or play.

**At what point from realizing there was going to be an accident to arrival at hospital.

5. I felt as though I were a spectator watching what was happening to me, as if I were floating above the scene or observing it as an outsider.

**At what point from realizing there was going to be an accident to arrival at hospital.

6. There were moments when my sense of my own body seemed distorted or changed. I felt disconnected from my own body, or that it was unusually large or small.

**At what point from realizing there was going to be an accident to arrival at hospital.

7. I felt as though things that were actually happening to others were happening to me like I was being trapped when I really wasn't.

**At what point from realizing there was going to be an accident to arrival at hospital.

8. I was surprised to find out afterwards that a lot of things had happened at the time that I was not aware of, especially things I ordinarily would have noticed.

**At what point from realizing there was going to be an accident to arrival at hospital. 
9. I felt confused, that is, there were moments when I had difficulty making sense of what was happening.

**At what point from realizing there was going to be an accident to arrival at hospital.

10. I felt disoriented, that is, there were moments when I felt uncertain about where I was or what time it was.

**At what point from realizing there was going to be an accident to arrival at hospital. 


\section{Mastery Scale}

Below are some statements people generally make about themselves. Tell me how much you agree or disagree with the following statements, using the following choices:

1

Strongly Agree
2

Somewhat Agree
3 Somewhat Disagree Strongly Disagree

1. I have little control over the things that happen to me.

2. There is really no way I can solve some of the problems I have.

3. There is little I can do to change many of the important things in my life.

4. I often feel helpless in dealing with the problems of life.

5. Sometimes I feel I'm being pushed around in life.

6. What happens to me in the future mostly depends on me.

7. I can do just about anything I set my mind to do. 